九州大学学術情報リポジトリ

Kyushu University Institutional Repository

\title{
Taxon-based Entomology Database KONCHU on INTERNET and its Usage
}

Tadauchi, 0samu

Inoue, Hitoshi

Takematsu, Yoko

https://doi.org/10.5109/2634

出版情報: ESAKIA. 39，pp.53-62，1999-03-31. Entomological Laboratory，Faculty of Agriculture， Kyushu University

バージョン :

権利関係 : 


\title{
Taxon-based Entomology Database KONCHU on INTERNET and its Usage ${ }^{1), 2 \text {, }}$
}

\author{
Osamu TADAUChi \\ Entomological Laboratory, Faculty of Agriculture, \\ Kyushu University, Fukuoka, 812-8581 Japan \\ Hitoshi INOUE \\ Computation Center, Kyushu University, Fukuoka, 812-8581 Japan \\ and \\ Yoko TAKEMATSU \\ Institute of Tropical Agriculture, Kyushu University, Fukuoka, 812-8581 Japan
}

\begin{abstract}
A taxon-based entomology database KONCHU is open to the public on INTERNET as well as in the Computer Center of Kyushu University. It is based on main Japanese entomological journals and treats a taxon, e.g. species, genus, family, as one record. Each record is composed of 13 items, such as bibliographical, taxonomical, distributional data and key words. Examples of the use of the KONCHU using the database management system SIGMA are presented. A user can access to the file by retrieving the following URL: http://konchudb.agr.agr.kyushu-u.ac.jp/.

Key words: entomology database, network, public use, KONCHU, INTERNET, SIGMA.
\end{abstract}

A publically available entomology database KONCHU is a general database name which includes various files of bibliographical databases. It is a taxon-based entomology database based on the main Japanese entomological journals and treats a taxon as one record, i. e., species, genus, family, etc. Each record is composed of 13 items, such as bibliographical, taxonomical, distributional data and key words. It has been open to the public at Computer Center of Kyushu University since 1987. The files of database KON-

1) Contribution from the Entomological Laboratory, Faculty of Agriculture, Kyushu University, Fukuoka (Ser. 5, No. 27).

2) This work was partly supported by a Grant-in-Aid for Publication of Scientific Research Result (Head Investigator: O. Tadauchi) and a Grant-in-Aid for Scientific Research (No. (B)(2) 09490028, (Head Investigator: O. Tadauchi)) both from the Ministry of Education, Science, Sports and Culture, Japan. 
CHU are managed by a text database management system SIGMA (Arikawa et al., 1987. 1988) working at the Computer Center of Kyushu University. The system SIGMA has recently modified for use on a work station. Therefore the KONCHU is repro-duced on a work station in the Entomological Laboratory, Kyushu University and is open to the public on INTERNET as well as from the Computer Center of Kyushu Uni-versity.

A user can access to the KONCHU by retrieving the following URL: http://konchudb. agr.agr.kyushu-u.ac.jp/. Outline and usage of the KONCHU are shown in Tadauchi $(1987,1994,1996)$, some files in the KONCHU are summarized in Tadauchi (1985: MUSHI file), Tadauchi (1994, ESAKIA file), Tadauchi \& Takematsu (1995: AKITU \& TMU files), Tadauchi et al. (1997: INMS file), and Takematsu et al. (1996: SHIKOKU file) and usage of the SIGMA system is explained in Arikawa et al. (1987, 1988).

The home page and examples of the use of the KONCHU using the SIGMA are presented in Figs. 1-8.

\section{Acknowledgments}

We are grateful to the members of the Entomology Database Project Group of Kyushu University. We are also indebted to Prof. S. Arikawa, Head of the SIGMA Project Group of Kyushu University and Prof. J. Yukawa and Prof. Emeritus Y. Hirashima of Kyushu University for their various help.

\section{References}

Arikawa, S. et al., 1987, A text database management system SIGMA, Version 2. Koho, Computer Center Kyushu Univ., 20: 517-581. (In Japanese)

Arikawa, S. et al., 1988, SIGMA: A text database management system. RIFIS Techn. Rep. Res. Inst. Fundam. Inform. Sci., Kyushu Univ., CS-3: 1-16.

Tadauchi, O., 1985, A list from a database DMUSHI produced in the Computer Center of Kyushu University. Mushi, 50: 47-175.

Tadauchi, O., 1987, A public database of entomology KONCHU and its usage. Koho, Computer Center Kyushu Univ., 20: 597-614. (In Japanese)

Tadauchi, O., 1994, ESAKIA file, one of the public taxon-based entomology database KONCHU produced at the Computer Center of Kyushu University. Escikia, (34): 227-237.

Tadauchi, O., 1996, Database production of species information in insects. In Computer Center of Kyushu University (ed.), Essays Contributed in Celebration of the 25th Anniversary of Computer Center of Kyushu University, pp. 156-166, Fukuoka. (In Japanese)

Tadauchi, O. \& Y. Takematsu, 1995, Two files, AKITU and TMU, in a taxon-based entomology database KONCHU produced at Computer Center of Kyushu University for public use on an on-line network. Jpn. J. Ent., 63: 539-540.

Tadauchi, O., Y. Takematsu \& H. Inoue, 1997, INMS file, in a taxon-based entomology database KONCHU produced at Computer Center of Kyushu University for public use on an on-line network. Jpn. J. Ent., 65: 847-849. 
Takematsu, Y., O. Tadauchi, Y. Higashiura, T. Omori \& H. Inoue, 1996, SHIKOKU file, in a taxon-based entomology database $\mathrm{KONCHU}$ produced at Computer Center of Kyushu University for public use on an on-line network. Jph. J. Ent., 64: 615616.

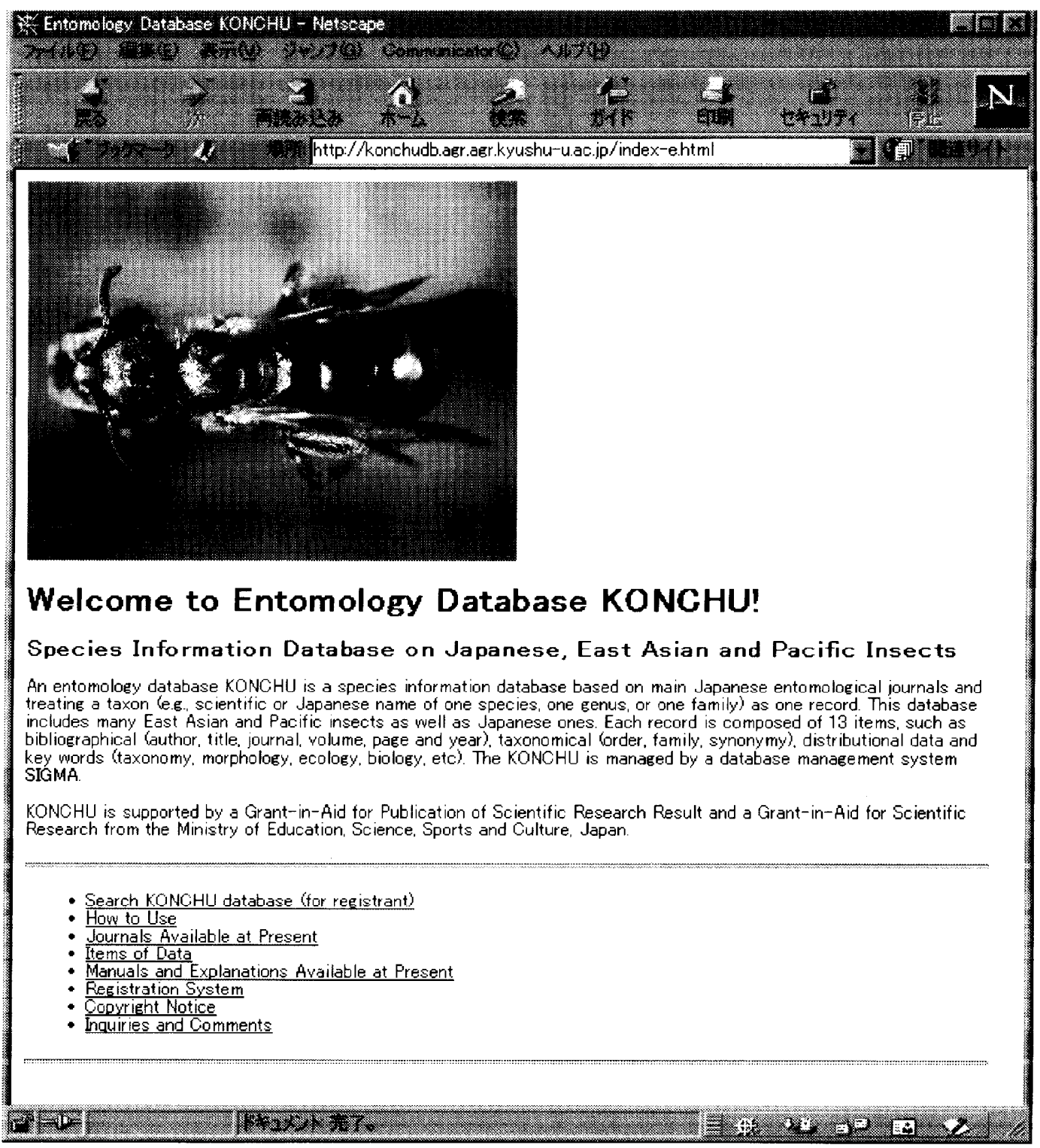

Fig. 1. A home page of a taxon based entomology database KONCHU in English version. A Japanese version is also available. URL: http://konchudb. agr.agr. kyushu-u.ac.jp/. 


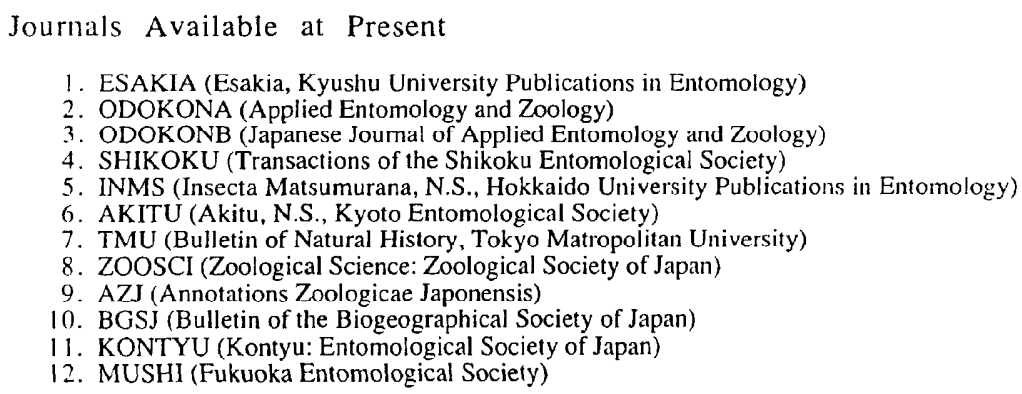

\section{Items of Data}

Items of Data and Tugs are the Following 13 items.

1. (TAX) taxon name (scientific name)

2. (JTAX) taxon name (Japanese name)

3. (AU) author

4. (T) title of the paper

5. (J) joumal

6. (VNP) volume, number, page

7. (Y) year

8. (OR) order

9. (FAM) family

10. (SYN) synonymy

11. (DST) distribution

12. (KEY) key words

13. (NOTE) note

Manuals and Explanations Available at Present

- Tadauchi, O., 1985, A list from a database DMUSHI produced in the Computer Center of Kyushu University. Mushi, 50: 47-175.

- Tadauchi, O., 1987, A public database of entomology KONCHU and its usage. Koho, Computer Center Kyushu Univ., 20 597-614. (In Japanese)

- Tadauchi, O., 1994, ESAKIA file, one of the public taxon-based entomology database KONCHU produced at the Computer Center of Kyushu University. Esakia, (34): 227-237.

- Tadauchi, O., 1996, Database production of species information in insects. In Computer Center of Kyushu University (ed.), Essays Contributed in Celebration of the 25th Anniversary of Computer Center of Kyushu University, pp. 156-166, Fukuoka. (In Japanese)

- Tadauchi, O. \& Y. Takematsu, 1995, Two files, AKITU and TMU, in a taxon-based entomology database KONCHU produced at Computer Center of Kyushu University for public use on an on-line network. Jpn. J. Ent., 63: 539-540.

- Tadauchi, O., Y. Takematsu \& H. Inoue, 1997, INMS file, in a taxon-based entomology database KONCHU produced at Computer Center of Kyushu University for public use on an on-line network. Jpn. J. Ent., 65: 847-849.

- Takematsu, Y., O. Tadauchi, Y. Higashiura, T. Omori \& H. Inoue, 1996, SHIKOKU file, in a taxon-based entomology database KONCHU produced at Computer Center of Kyushu University for public use on an on-line network. Jpn. J. Ent., 64: 615-616.

Fig. 2. A home page of a taxon based entomology database KONCHU in English version. It shows lists of (1) journals available at present, (2) items of data and (3) manuals and explanations available at present. Each taxon (e.g. species, genus, family) is extracted from main Japanese entomological journals as one record and composed of 13 items, such as bibliographical, taxonomical, distributional data and key words. 


\section{How to Use Entomology Database KONCHU}

\section{Simple Search}

\section{Advanced Search}

To go back to the previous page, please click the back button on your browser.

\section{Simple Search}

In the simple search mode, you can search the database by defining a simple logical formula composed of key words (and their items by request) and AND/OR/BUT NOT operators.

Fure 1 shows an initial screen of the simple search.

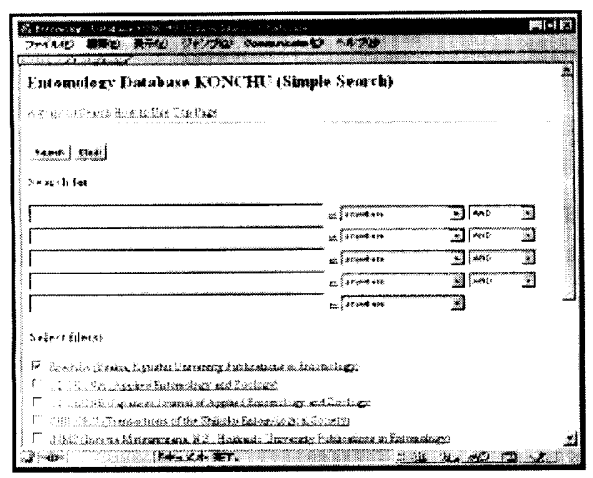

Iiig. I. An initial sereen of the simple search.

How to search

1. Keyword

Type a keyword in the input box

2. Item Sclect an item of the keyword from a pull down menu. To search the keyword from all items, select anyohere (delauls)

3. Logrical operator

Select a logical operator (AND or OR Or BUT NOT) from the pull down menu if you enter morc than one keyword

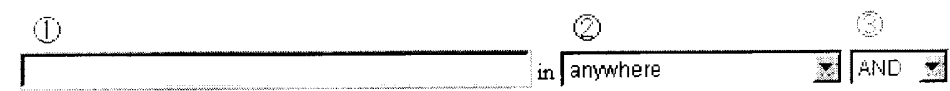

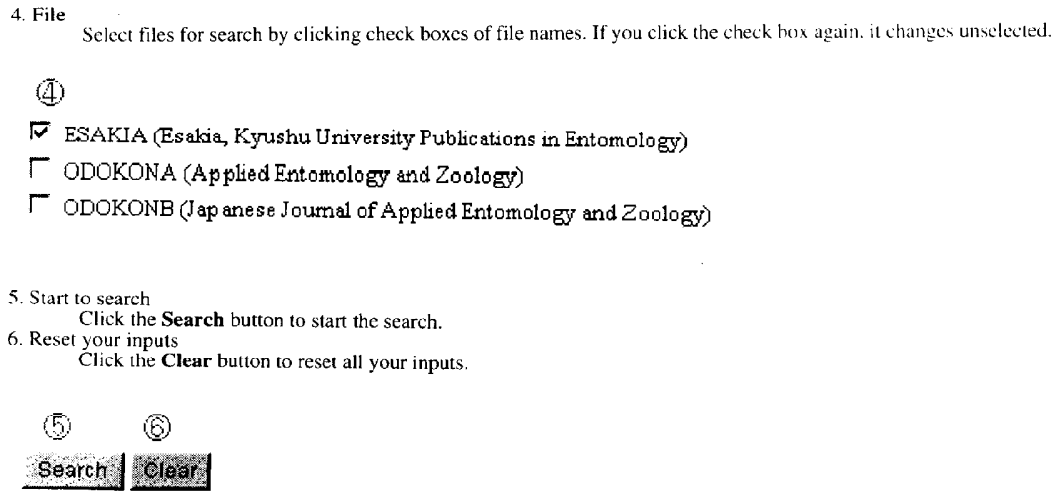

Fig. 3. Explanation of usage of the entomology database KONCHU in the home page, "How to use entomology database KONCHU". Simple search. 


\section{Advanced Search}

In the advanced search mode, you can search the database by specifying more complicated logical formulas composed of keywords (their items for request), logical operators, comparison operators and arithmelic operators. The search is performed keywords (their items
simultaneously.

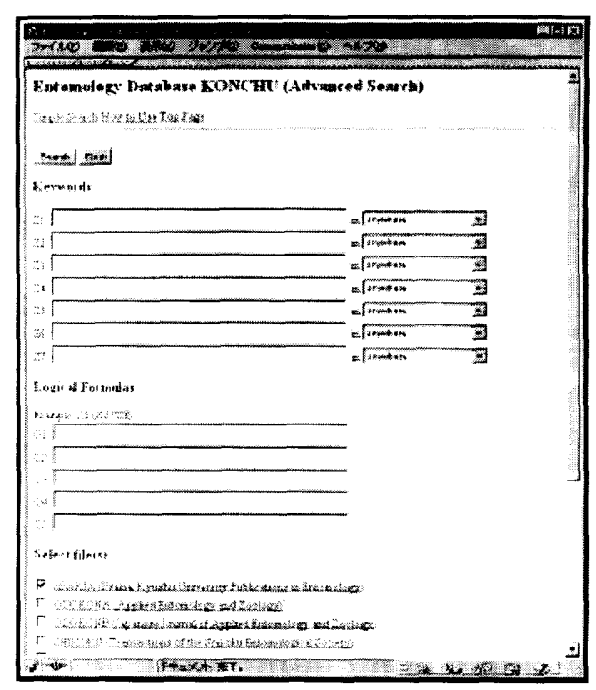

Fig. 5. An initial screen of the advanced search.

How to search

1. Keyword

Type a keyword in the input box.

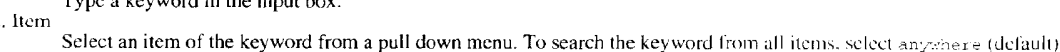

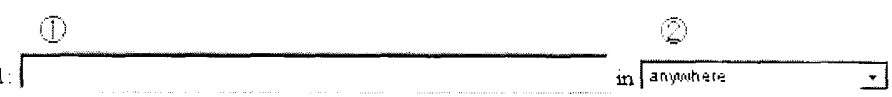

3. Logical formula

Make logical formula out of keywords and their items which are defined at the stage 1 and I lectail is here)

Q1:

4. File

Select files for search by clicking check boxes of file names. If you click the check box again. il changes uncelected

(4)

T ESAKIA (Esakia, Kyushu University Publications in Entomology)

$\Gamma$ ODOKONA (Applied Entóthology and Zoology)

$\Gamma$ ODOKONB (Jap anese Journal of Applied Entomology and Zoology)

5. Start to search

Click the Search button to start the search.

6. Reset your inputs

Click the Clear button to reset all your inputs.

(5)

(6)

seavidian

Fig. 4. Explanation of usage of the entomology database KONCHU in the home page, "How to use entomology database KONCHU". Advanced search. 

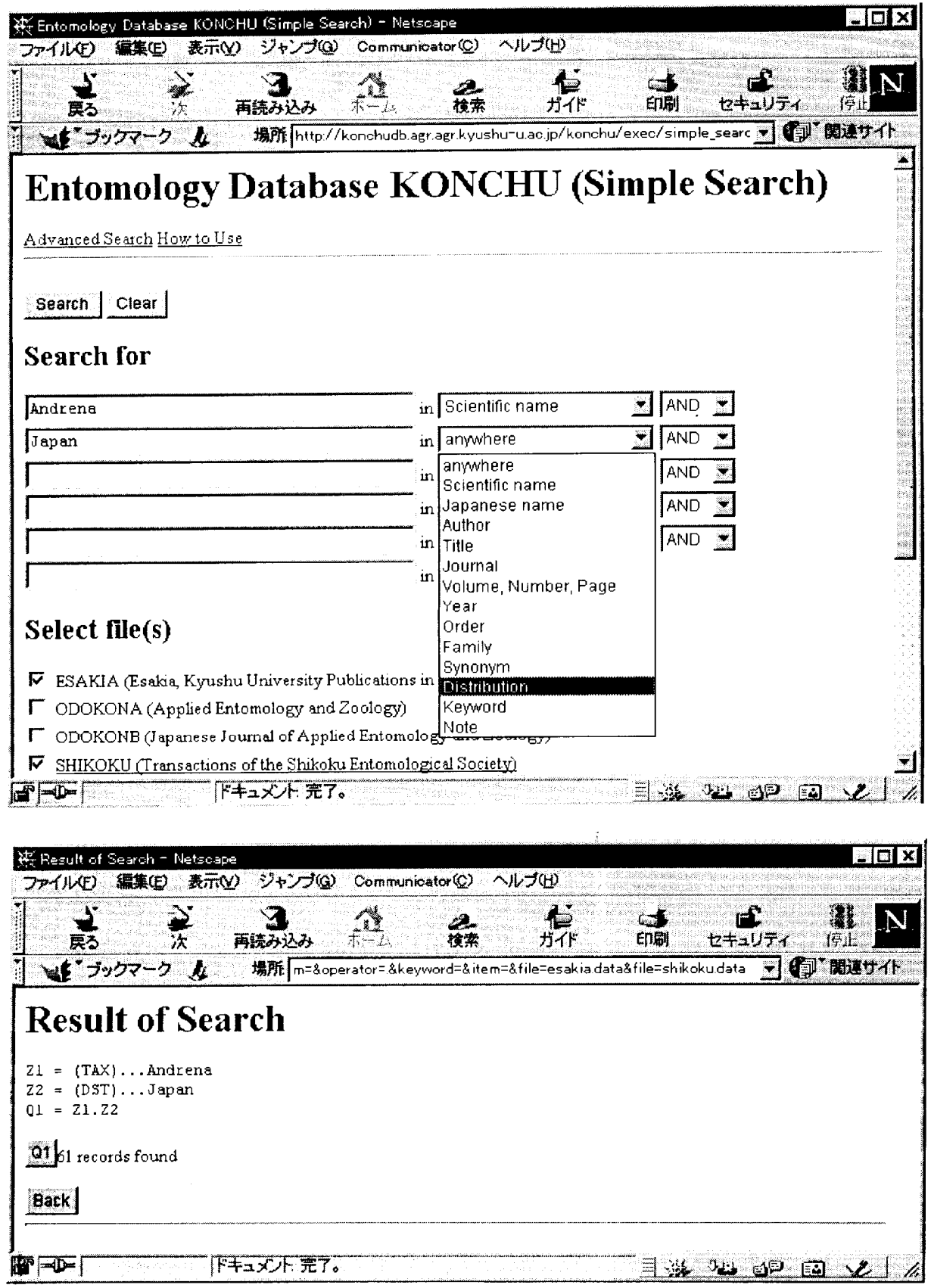

Fig. 5. Explanation of usage of the entomology database KONCHU in the home page "Example of simple search". The upper screen shows that 2 keywords, Andrena in the item "scientific name" and Japan in the item "distribution" are defined and 2 files, ESAKIA and SHIKOKU are selected. In the screen, the item for the 2 nd keyword is just selecting from the pull down menu. The lower screen shows the result of search, 61 records are found. 


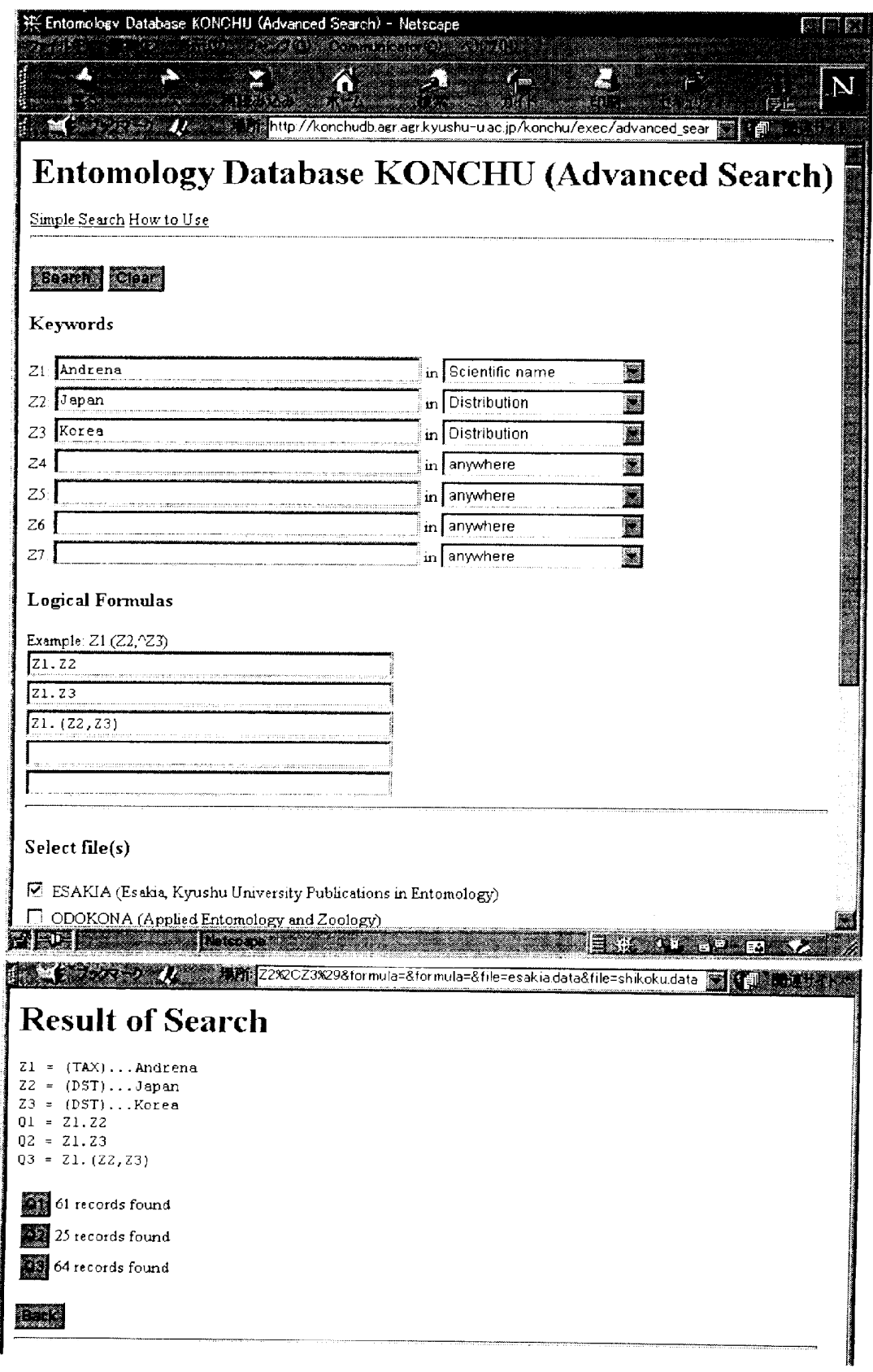

Fig. 6. Explanation of usage of the cntomology database KONCHU in the home page "Example of advanced search". The upper screen shows that 3 keywords, Andrena in the item "scientific name", Japan in the item "distribution" and Korea in the item "distribution" are defined as $Z 1, Z 2$ and $Z 3$, respectively. $\mathrm{Z} 1 . \mathrm{Z2}(=\mathrm{Z1}$ and $\mathrm{Z} 2), \mathrm{Z1.Z3}(=\mathrm{Z} 1$ and $\mathrm{Z3})$ and $\mathrm{Z} 1 .(\mathrm{Z} 2, \mathrm{Z} 3)(=\mathrm{Z} 1$ and $(\mathrm{Z} 2$ or $\mathrm{Z3}))$ and the file "ESAKIA" is selected. The lower screen shows the result of search, 61,25 and 64 records are found, respectively. 


\section{Result of Search}

(TAX) Andrena (Gymnandrena) okabei sapporensis Hirashima

(AU) HIRASHIMA, Yoshihiro;TADAUCHI, 0samu;SUDA, Hirohisa

(T) New or little known bees of Japan (Hymenoptera, Apoidea) I. Supplementary note on two Andrena species

(J) Esakia

(VNP) (14): $135-139$

(Y) 1979

(OR) Hymenoptera

(FAM) Andrenidae

(DST) Japan(Hokkaido, Honshu, Kyushu)

(KEY) systematics; description(male); floral record;flight records; remarks

(TAX) Andrena (Euandrena) ruficrus rabicrus Hirashima

(AU) HIRASHIMA, Yoshihiro;TADAUCHI, Osamu;SUDA, Hirohisa

(T) New or little known bees of Japan (Hymenoptera, Apoidea) I. Supplementary note on two Andrena species

(J) Esakia

(VNP) (14): 139-143

(Y) 1979

(OR) Hymenoptera

(FAM) Andrenidae

(DST) Japan(Hokkaido, northern \& central Honshu)

(KEY) systematics; description(male); floral records; flight records; remarks

(TAX) Andrena

(AU) TADAUCHI, Osamu

(T) Taxonomic working system by computer (SAC) with application to Japanese Andrenid bees

(J) Esakia

(VNP) (17): 161-182

(Y) 1981

(OR) Hymenoptera

(FAM) Andrenidae

(DST) Japan

(KEY) taxonomic working system; computer;SAC; include 17 programs; character analysis; taxa grouping; specimen i

(TAX) Andrena Fabricius

(AU) TADAUCHI, Osamu

(T) Factor analysis of integumental sculptures in the Japanese Andrenid bees

(J) Esakia

(VNP) (19): 135-150

(Y) 1982

(OR) Hymenoptera

(FAM) Andrenidae

(KEY) factor analysis; character correlation; integumental sculptures; Andrena; Japan; 9 common factors; biologic

(TAX) Andrena (Simandrena)

(AU) TADAUCHI, Osamu; HIRASHIMA, Yoshihiro

(T) New or little known bees of Japan (Hymenoptera, Apoidea) IV. Supplements to Andrena (Simandrena)

(J) Esakia

(VNP) (20): 81-92

(Y) 1983

(OR) Hymenoptera

(FAM) Andrenidae

(DST) Japan

(KEY) systematics; key to Japanese spp.; contain 4 spp.; include 2 new spp. \& 1 new subsp.

Fig. 7. Example of result of a search of the entomology database KONCHU. Two keywords, Andrena and Japan are defined and shows the first some records. 


\section{2 O. TADAUCHI, H. INOUE \& Y. TAKEMATSU \\ Result of Search}

Push the following buttons to display the results

Chalcidoidea
Encyrtidae
biology
parasite
host
Z1.Z2.Z3.Z4.Z5

\begin{tabular}{|c|c|c|c|c|}
\hline \multicolumn{5}{|c|}{$\begin{array}{l}\text { Searching shikoku.data } \ldots \\
\text { RETRIEVED RECORDS }\end{array}$} \\
\hline QUESTION & $1\left(\begin{array}{ll}2 & 1\end{array}\right)$ & $=$ & 636 & 636 \\
\hline QUESTION & $2\left(\begin{array}{ll}z & 2\end{array}\right)$ & $=$ & 590 & 590 \\
\hline QUESTION & $3\left(\begin{array}{ll}2 & 3\end{array}\right)$ & $=$ & 852 & 852 \\
\hline QUESTION & $4(24)$ & $=$ & 59 & 59 \\
\hline QUESTION & $5(z 5)$ & $=$ & 943 & 943 \\
\hline QUESTION & $6(26)$ & $=$ & 3 & \\
\hline TOTAL & & $=$ & 1145 & 1145 \\
\hline CPU TIME & & $=$ & 0.540 & 0.540 \\
\hline
\end{tabular}

\section{Result of Search}

(TAX) Comperiella unifasciata Ishi

(JTAX)

(AU) TACHIKAWA, Tetsusaburo

(T) Some notes on the male of Comperiella unifasciata Ishi i (Hymenoptera: Encyrtidae)

(J) Transactions of the Shikoku Entomological Society.

(VNP) $3(7)$ : 181-183, (181-183)

(Y) 1953

(OR) Hymenoptera, 八チ目

(FAM) Encrytidae, トビコバチ科

(SYN)

(DST) Japan(new record:Shikoku, Kyushu); Java

(XEY) taxonomy; new record; remarks

(NOTE)

(TAX) Comperiella bifasciata

(JTAX)

(AU) TACHIKAWA, Tetsusaburo

(T) Some notes on the male of Comperiella unifasciata Ishii (Hymenoptera: Encyrtidae)

(J) Transactions of the Shikoku Entomological Society

(VNP) $3(7)$ : 181-183, (181-183)

(Y) 1953

(OR) Hymenoptera, 八千目

(FAM) Encrytidae,トビコバチ科

(SYN)

(DST)

(KEY) taxonomy

(NOTE)

Fig. 8. Example of a search of the entomology database KONCHU. Five keywords, Chalcidoidea, Encyrtidae, biology, parasite and host are defined and the file SHIKOKU is selected. The result shows the first 2 records of search for the question $2(=\mathrm{Z} 2)$. 